Archived version from NCDOCKS Institutional Repository http://libres.uncg.edu/ir/asu/

Roy, J. (2010). Do customs union members engage in more bilateral trade than free-trade agreement members? Review of International Economics, 18(4), 663-681. doi:10.1111/j.1467-9396.2010.00904.x

\title{
Do Customs Union Members Engage in More Bilateral Trade than Free-Trade Agreement Members?
}

Jayjit Roy

\begin{abstract}
This paper provides the first empirical analysis directly comparing the effects of customs unions (CUs) and free-trade agreements (FTAs) on members' bilateral trade, while addressing the biases arising from loglinearization of the gravity model and crucial timeinvariant unobservables. Since Fiorentino et al. (2007) question the popularity of CUs relative to FTAs, considering the latter to be more practical in the current trading climate, such a comparison seems especially relevant. While Baier and Bergstrand (2007) find an FTA to approximately double members' bilateral trade after 10 years, the results of this paper find CUs to have had a much larger impact than FTAs.
\end{abstract}




\section{Introduction}

In today's trading climate, the relevance of analyzing preferential trade agreements (PTAs) cannot be overemphasized. The effective number of such agreements exceed 200, with Mongolia being the only World Trade Organization (WTO) member not party to one. The notification of more than 50 PTAs to the WTO between January 2005 and December 2006, coupled with the ongoing negotiations of numerous agreements, indicate their recent proliferation and unabated rise in years to come. If all the PTAs currently under negotiation and proposal are implemented, then one would be looking at over 400 PTAs by 2010 (Fiorentino et al., 2007). Hence, policy issues associated with trade agreements are relevant for some time to come.

Any PTA is essentially an arrangement among countries whereby members engage in trade at reduced tariff rates. If the members eliminate tariffs internally while maintaining their individual external tariffs, a free-trade area or free-trade agreement (FTA) is formed. In case they also unify their external tariffs, the arrangement is termed a customs union (CU). Prominent FTAs include the North American Free Trade Agreement (NAFTA), whereas Mercosur comprises an example of a CU.

The literature on preferential agreements has addressed a host of associated policy issues. Unfortunately, analyses pertaining to a comparison of the types of PTAs have received relatively less attention. Perhaps Krueger (1997, p. 171) best expresses this, stating: "Surprisingly . . . there has been little analysis of different types of preferential arrangements, and in particular, of free trade agreements in contrast to customs unions." Clausing (2000), the only contribution to the author's knowledge after Krueger (1997) in terms of directly comparing FTAs and CUs, also alludes to this lack of attention. However, both Krueger (1997) and Clausing (2000) are theoretical contributions. Accordingly, the empirical literature seems to be even more lacking in this respect. This paper fills the gap by analyzing a straightforward question: do countries belonging to a $\mathrm{CU}$ engage in more bilateral trade (in goods) on average than countries belonging to an FTA?

Such a comparison of FTAs and CUs is of great relevance. With their greater recent proliferation relative to CUs, FTAs account for $84 \%$ of all the PTAs notified and in force (Fiorentino et al., 2007). The proportion of FTAs to CUs is even higher if one considers the PTAs currently under negotiation. Accordingly, Fiorentino et al. $(2007$, p. 5) question the popularity of CUs and consider them to be "out of tune with today's trading climate." In light of this, the findings of this paper are especially significant.

Using the gravity model and data from Baier and Bergstrand (2007, BB hereafter), this paper compares the effects of FTAs and CUs on members' volume of bilateral trade.While doing this, two sources of potential bias are recognized. First, as suggested by BB (2007), cross-section estimates of the PTA coefficients suffer from a potential bias if country-pairs select into agreements on the basis of time-invariant unobservables. Second, Santos Silva and Tenreyro (2006) invoke Jensen's inequality and recommend estimating gravity models using the Poisson pseudo-maximum likelihood (PPML) estimator as ordinary least squares (OLS) estimates may be biased if 
the PPML specification suffers from heteroskedasticity. Once the biases arising from crucial unobservables, or log-linearization of the gravity model are addressed, the results are striking. BB (2007, p. 72) find that, "on average, an FTA approximately doubles two members' bilateral trade after 10 years." However, using the same data, the results of this paper indicate that it is a CU, and not an FTA, which is responsible for this. More generally, members of a $\mathrm{CU}$ are found to engage in significantly greater volumes of bilateral trade than FTA members. Hence, analyses which do not allow for the effects of FTAs and CUs to differ, fail to capture this crucial aspect of trade policy decisions.

\section{Empirical Methodology}

\section{Cross-Section Analysis}

Gravity models are estimated using the PPML estimator and OLS to compare the effects of FTAs and CUs. The specification for the PPML method is given by

$$
T_{i j}=\beta_{0} D_{i j}^{\beta_{1}} \exp \left(\beta_{2} \text { lang }_{l j}+\beta_{3} \text { adj }_{i j}+\beta_{4} F T A_{i j}+\beta_{5} C U_{t j}+\theta_{t}+\theta_{j}\right) \eta_{i j} .
$$

Here, $T i j$ is the nominal value of exports from country $i$ to country $j$; Dij is the distance between $i$ and $j$; langij is a dummy variable taking the value one if $i$ and $j$ share a common language (zero otherwise); adjij is a binary variable assuming the value unity if $i$ and $j$ share a land border (zero otherwise); FTAij (CUij) is a dummy variable taking the value one if $i$ and $j$ are part of an FTA (CU) and zero otherwise; and qi and q $j$ are country-specific dummies.3 Santos Silva and Tenreyro (2006) show that (1) may be estimated using an estimator that is numerically equivalent to the PPML estimator, provided

$$
\mathrm{E}\left[\eta_{l j} \mid D_{l l}, \text { lang }_{l,}, \operatorname{adj}_{j_{l},}, F T A_{\ell /}, C U_{t l}, \boldsymbol{\theta}_{l}, \boldsymbol{\theta}_{j}\right]=1 \text {. }
$$

The OLS specification is instead given by

$$
\begin{aligned}
\ln T_{i j}= & \ln \beta_{0}+\beta_{1} \ln D_{i j}+\beta_{2} \text { lang }_{i j}+\beta_{3} a d j_{l j}+\beta_{4} F T A_{i j}+\beta_{5} C U_{i j} \\
& +\theta_{t}+\theta_{f}+\ln \eta_{i j} .
\end{aligned}
$$

Consistent estimation of (3) requires

$$
\mathrm{E}\left[\ln \eta_{i j} \mid D_{i j}, \operatorname{lang}_{i j}, \operatorname{adj}_{i j}, F T A_{t j}, C U_{i j}, \theta_{i}, \theta_{j}\right]=0 .
$$

However, as noted by Santos Silva and Tenreyro (2006), (2) does not imply (4) (invoking Jensen's inequality); in fact, the OLS elasticity estimates may be biased if the PPML specification suffers from heteroskedasticity. Henderson and Millimet (2008) find this concern relevant and recommend estimating the gravity model using the PPML. This also avoids the omission of observations with zero trade flows or the use of other ad hoc measures to address it. 
Panel Analysis

The cross-section estimates are likely to be biased due to endogenous trade agreements. An excellent account of the endogeneity issue, and the failure of previous cross-section studies to address it, can be found in BB (2007). Although Magee (2003) attempts to address it by relying on instrumental variables (IV), the quality of the instruments used is clearly suspect. It is unlikely that variables like GDP similarities or differences in relative factor endowments between two countries are uncorrelated with unobservables affecting the volume of trade between them. Moreover, the difficulty of coming up with a valid instrument in the context of trade agreements compels BB (2007, p. 83) to conclude that "IV estimation is not a reliable method for addressing the endogeneity bias."

The panel fixed effects approach, with pairs of countries as the basic unit of observation, addresses the endogeneity issue to a certain extent. It allows one to control for pairwise time-invariant unobservables which affect the volume of trade between two countries, and are also correlated with their decision to form an agreement. Hence, the panel fixed effects estimates are a definite improvement over the cross-section estimates.

However, the bias arising from the OLS specification is a separate issue. Panel OLS estimates may still be biased and lead to "misleading conclusions" in the presence of heteroskedasticity in the PPML model (Santos Silva and Tenreyro, 2006, p. 641). In keeping with this recommendation and the ones in Henderson and Millimet (2008) and Liu (2009), the panel analysis is mainly conducted using the PPML specification which is given by

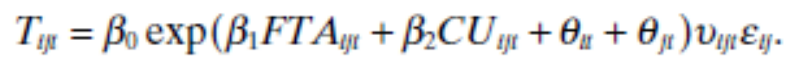

In this case, $T_{i j t}$ is the real value of exports from country $i$ to country $j$ at time $t$. While distance, language, and adjacency drop out of (5), being captured by the panel fixed effects, the other variables have an additional $t$ subscript. Accordingly, FTAijt $\left(C U_{i j t}\right)$ takes the value one if $i$ and $j$ are part of an FTA (CU) at time $t$ and zero otherwise; and $\mathrm{q}_{i t}$ and qit are the country-by-time dummies. The unobservable term is decomposed into time-varying and time-invariant components such that $h_{i j t}=u_{i j t e i t .}$. The panel fixed effects method provides consistent estimates even in the presence of any correlation between the time-invariant unobservables eij and the trade agreement dummies.

While trade agreements usually have a phase-in period, some of the effects may actually precede the date of the agreement. Hence, some of the panel specifications include lag and lead terms of the trade agreement dummies to capture any lagged or anticipatory effects. BB (2007, p. 90) also recommend the inclusion of lag terms since trade agreements involve changes in countries' terms of trade, which "tend to have lagged effects on trade volumes." In other words, some panel specifications include variables like $F T A_{i j, t-k}$ and $C U_{i j, t-k,}$ or $F T A_{i j, t+k}$ and $C U_{i j, t+k}$. The variable $F T A_{i j, t-k}\left(C U_{i j, t-k}\right)$ is simply the $k$ th lag of $F T A_{i j t}\left(C U_{i j t}\right)$ and captures the lagged effects of the FTA (CU). 
Similarly, the variable $F T A_{i j, t+k}\left(C U_{i j, t+k}\right)$ is the $k$ th lead of $F T A_{i j t}\left(C U_{i j t}\right)$ and captures any anticipatory effect.

\section{The Data}

The data come from BB (2007); thus, only limited details are provided. The nominal bilateral trade flows are from the International Monetary Fund's Direction of Trade Statistics for the years 1960 to 2000, at five-year intervals. For the panel analysis, exporter GDP deflators are used to generate the real trade flows. The bilateral distances and the language and adjacency dummies are calculated from the $\mathrm{CIA}$ Factbook. Although the trade agreement dummies continue to be defined by an agreement's year of entry, they involve a crucial modification. While BB (2007) considered a single dummy variable, which pooled the "full (no partial) FTAs and customs unions" together, here their effects are allowed to differ (p. 84).

In keeping with the original data, the classification of trade agreements into the two PTA types is based on the sources listed in Table 3 in BB (2007). For further clarity, Table A1, in the Appendix, lists the FTAs and CUs considered along with the relevant years. In addition, the trade agreement dummy in the original data involved errors, which have been corrected.

\section{Results}

\section{Cross-Section Results}

Tables 1, 2, and 3 correspond to the cross-section results for the years 1960, 1970, . . , 2000.While Table 1 reports results using the OLS specification excluding observations with zero bilateral trade, Table 2 reports the OLS results after replacing the zeros by ones. The issue of dealing with the zero trade values does not arise in the PPML specification, whose results are presented in Table 3. For all the cross-section results, columns (a) and (b) do not consider separate dummies for FTAs and CUs, where (a) uses the original trade agreement dummy from BB (2007) and (b) reports results after incorporating the corrections to it.7 The coefficient estimates and their statistical significance hardly differ across (a) and (b) in any of the cross-section tables. Thus, the results of the paper are not sensitive to the corrections. Column (c) considers the differential effects of FTAs and CUs. Results from the OLS specifications (Tables 1 and 2) indicate mostly negative coefficients on the FTA and CU dummies. This is similar to the cross-section findings in BB (2007), who only offer omitted variables bias as an explanation. In Table 1, the null hypothesis of equality between the FTA and CU coefficients is rejected, at the $5 \%$ level, for all years except 1970. Table 2 reports a similar rejection for all years except 1960 and 1970. Hence, the cross-section OLS findings suggest that, post-1970, FTA and CU members engage in significantly different volumes of bilateral trade. For all instances of rejection of the null, in Tables 1 and 2, the coefficient on $\mathrm{CU}$ is more negative than the FTA coefficient.

Results from the PPML specification are strikingly different. The statistically significant coefficients on FTA and CU are all positive. The $p$-values, in Table 3 , signify a 
Table 1. Cross-Section Estimates of the OLS Specification (exc/uding observations with zero trade)

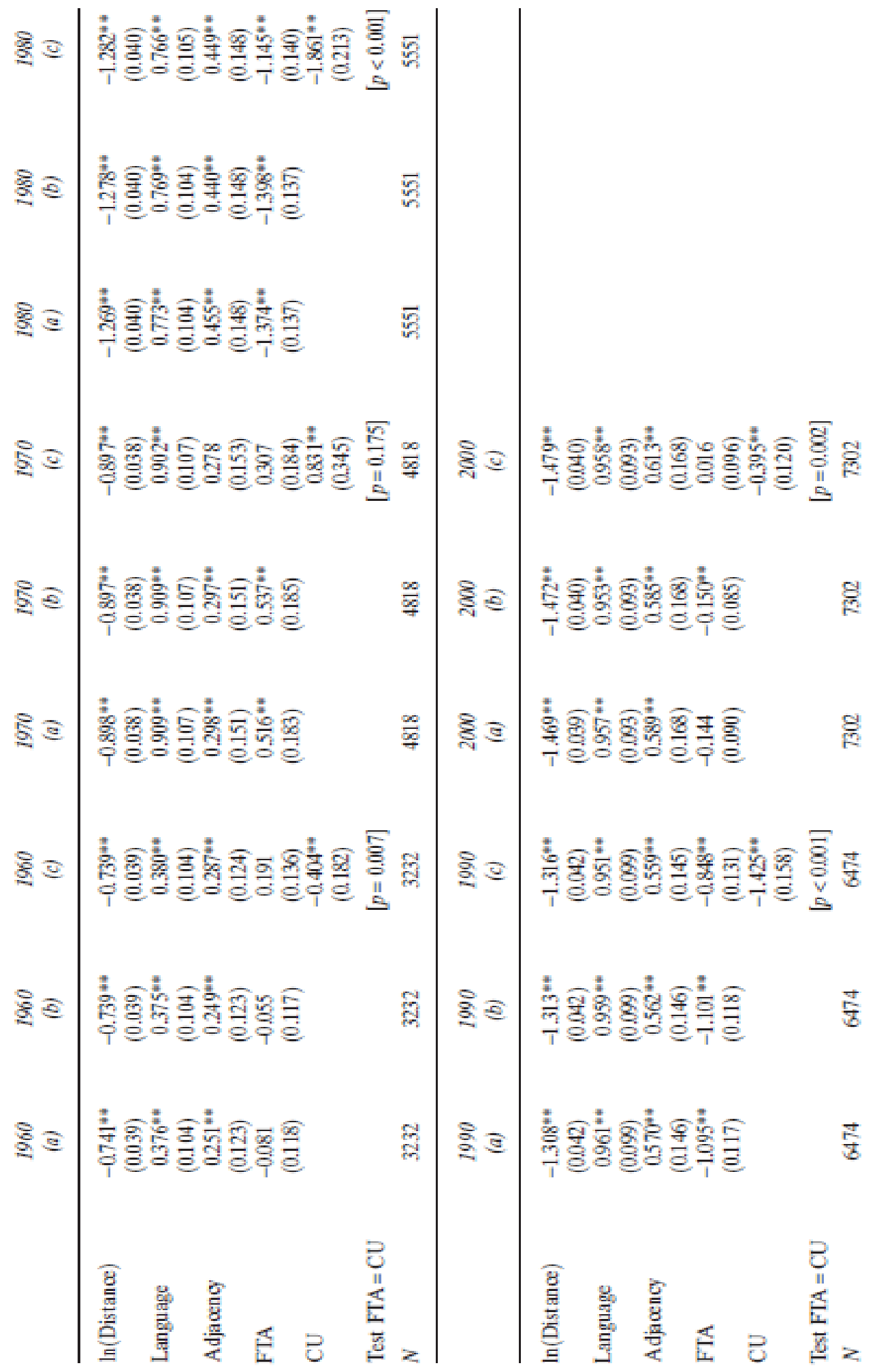


Table 2. Cross-Section Estimates of the OLS Specification (including observations with zero trade)

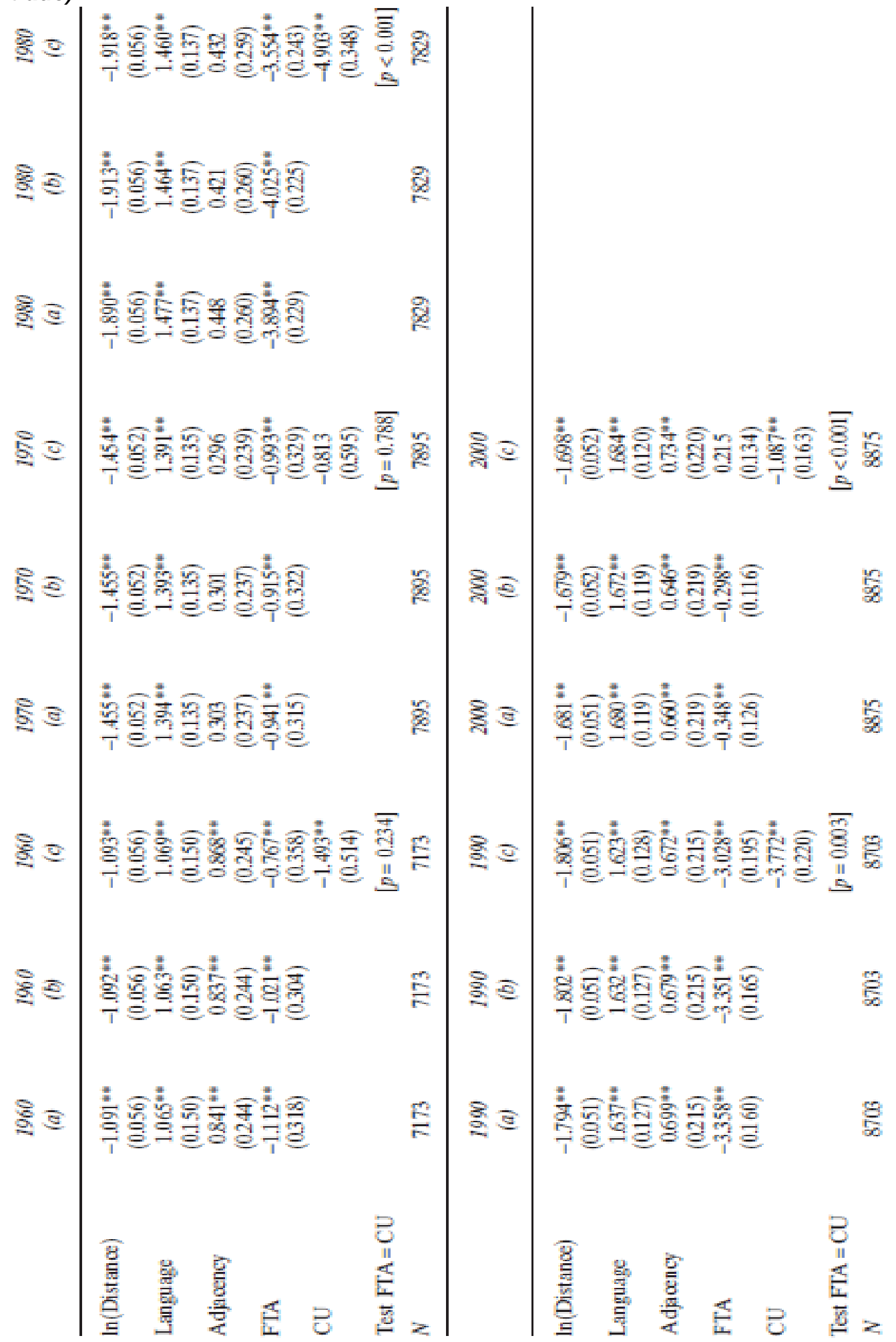


Table 3. Cross-Section Estimates of the PPML Specification (including observations with zero trade)

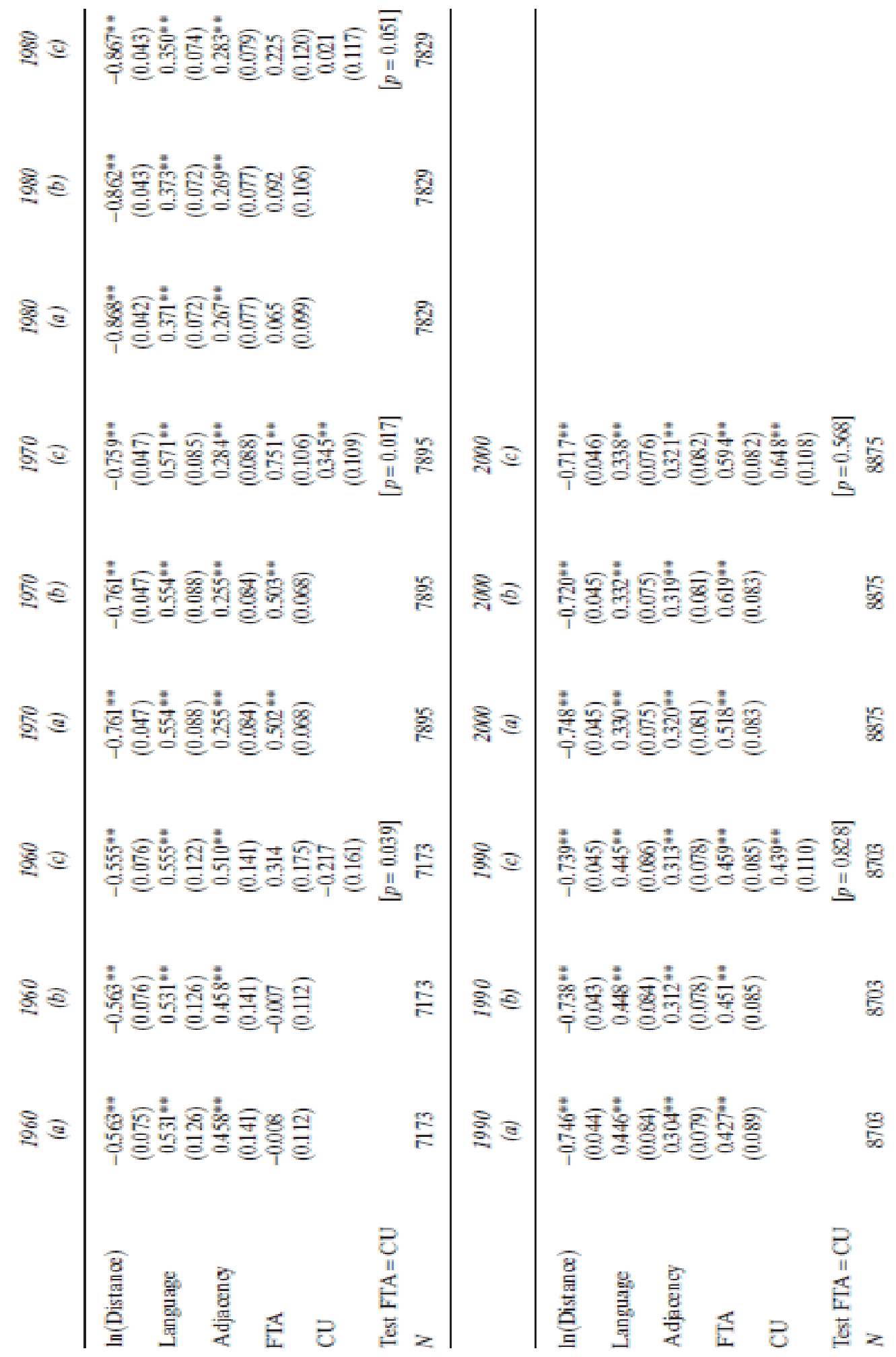


rejection of the null of equality for 1960 and 1970 only. Hence, the PPML results imply that the volume of bilateral trade is significantly different among FTA and CU members up to 1970. It will be interesting to see what the panel results have to offer. Santos Silva and Tenreyro (2006) also find striking differences in their Monte Carlo simulations, across the two cross-section specifications. They further claim that (p. 641), "OLS yields significantly larger effects for geographical distance." The results in Tables 1, 2, and 3 are consistent with this too. Thus, regardless of the endogeneity due to omitted variables, the potential endogeneity arising from the OLS specification seems to be of significant relevance by itself. In fact, the potential bias from using OLS is large enough to render the positive and significant PPML coefficient estimates insignificant, or even negative and significant. The cross-section findings further support PPML estimation.

\section{Panel Results}

Unlike the cross-section estimates, the panel results, reported in Table 4, allow for an unambiguous ranking of FTAs and CUs with respect to their effect on members' volume of bilateral trade. Column (a) does not consider any lagged or anticipatory effects of the trade agreements; (b) allows for single lags of FTA and CU; (c) considers two lags of each; and (d) allows for two lags and one lead. Across all specifications, the coefficients on CU are positive and significantly greater than the FTA coefficients. Individual and joint tests reject the equality of the coefficients on FTA and CU, and on their lag and lead terms, at the $1 \%$ level.

Column (a) indicates that an FTA increases members' bilateral trade by less than $17 \%$, on average, relative to countries not belonging to a CU or an FTA.9 However, a CU increases the same by about $77 \%$. The difference seems to be even more stark once the lagged and anticipatory effects in columns (b), (c), and (d) come into play. For each of these specifications, the cumulative effect of an FTA or a CU is obtained by adding the statistically significant lag, lead, and contemporaneous coefficients. The coefficients in (b) imply that while an FTA increases members' trade by about $25 \%$, a CU brings about an increase of more than $90 \%$, after five years.10 Similarly, the results in (c) find FTA and CU members to engage in $26 \%$ and $110 \%$ more bilateral trade, respectively, after a decade. This is reminiscent of the principal result in BB (2007, p. 72), who find that, "on average, an FTA approximately doubles two members' bilateral trade after 10 years." However, the results here hold only CUs responsible for this. Thus, pooling all FTAs and CUs into a single trade agreement dummy masks this crucial information.

Specification (d) continues to find CU members to engage in more bilateral trade while allowing for anticipatory effects of trade agreements. Unlike the findings in BB (2007), but similar to those in Magee (2008), these effects turn out to be significant. A closer look at the cross-section and panel PPML results, Tables 3 and 4, suggests that concern over possible selection bias is well-founded. The significant contemporaneous trade agreement coefficients are similar in sign across both. However, the same cannot be said of their magnitudes as the cross-section FTA coefficients are clearly more positive, whereas the CU coefficients are of similar magnitude in the cross-section and panel analyses. This suggests a positive selection bias for FTA members on the basis of time-invariant unobservables. Conversely, the 
similarity in magnitude of the significant contemporaneous CU coefficients across Tables 3 and 4 is consistent with a lack of nonrandom selection into CUs.

While the results are consistent with a lack of nonrandom selection into CUs, it is vital to note that the results do not contradict the existence of a negative selection bias

Table 4. Panel Estimates of the PPML Specification (including observations with zero trade)

FTA
Lag FTA
Lag2 FTA
Lead FTA
Cumulative FTA
CU
Lag CU
Lag2 CU
Lead CU
Cumulative CU
Test FTA $=$ CU
Test Lag FTA $=$ Lag CU
Test Lag2 FTA $=$ Lag2 CU
Test Lead FTA = Lead FTA
Joint test
$N$

(a)

$0.154^{* *}$

(0.0001)

$0.571^{\text {** }}$

(0.0001)
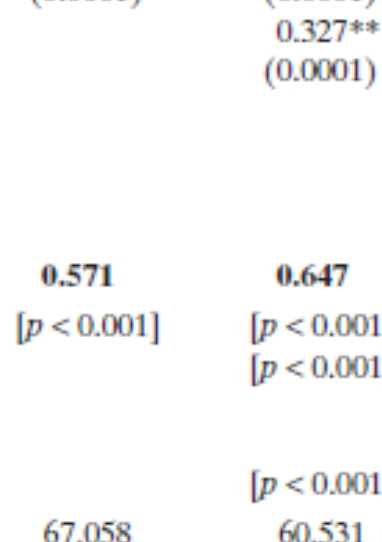

0.647

60,531 (b)

$0.074^{* *}$

(0.0001)

$0.149 * *$

(0.0001) (c)

$\begin{array}{cc}0.080^{* *} & 0.121^{* *} \\ (0.0001) & (0.0001) \\ 0.131^{* *} & 0.026^{* *} \\ (0.0001) & (0.0001) \\ 0.022^{* *} & 0.081^{* *} \\ (0.0001) & (0.0001) \\ & 0.039^{* *}\end{array}$

(0.0001)

$\mathbf{0 . 2 2 3}$
$0.320^{* *}$
$(0.0001)$
$0.327^{* *}$
$(0.0001)$

$$
[p<0.001]
$$$$
[p<0.001]
$$$$
[p<0.001]
$$

0.233

$0.342^{\text {** }}$

(0.0001)

$0.205^{* *}$

(0.0001)

$0.198^{* *}$

(0.0001)

0.745

$$
\begin{aligned}
& {[p<0.001]} \\
& {[p<0.001]} \\
& {[p<0.001]}
\end{aligned}
$$

0.267

$0.357^{* *}$

(0.0001)

$0.276 * *$

(0.0001)

0.157 **

(0.0001)

$0.069^{* *}$

(0.0001)

0.859

[p<0.001]

$[p<0.001]$

$[p<0.001]$

$[p<0.001] \quad[p<0.001]$

53,707

44,014 $[p<0.001]$

into FTAs found in BB (2007), or nonrandom selection into CUs. To see this, consider decomposing the error term in the gravity model into three components: unobservables that promote trade, unobservables that hinder trade, and an idiosyncratic component. While one example of the former might include past political affinity, Magee $(2003$, p. 1) provides additional examples while discussing "the natural trading partner hypothesis." Haveman and Hummels (1998, p. 62) also opine that "high levels of intra-bloc trade may be due not to the formation of preferential trading arrangements but rather to historical or political relationships between bloc members." On the other hand, BB (2007) offer the example of stringent internal shipping regulations as an unobservable that hinders trade. Now, countries might select into PTAs on the basis of both types of unobservable, and the nature of overall selection bias would depend on the dominant type.

By employing the OLS specification, BB (2007) find evidence of negative selection, which is also supported by the panel results from Tables 1 and 5 in this paper.

However, 
Table 5. Panel Estimates of the OLS Specification (excluding observations with zero trade)

\begin{tabular}{|c|c|c|c|c|}
\hline & (a) & (b) & (c) & (d) \\
\hline FTA & $\begin{array}{l}0.215^{* *} \\
(0.045)\end{array}$ & $\begin{array}{l}0.157^{* *} \\
(0.049)\end{array}$ & $\begin{array}{l}0.146 * * \\
(0.050)\end{array}$ & $\begin{array}{l}0.112 * * \\
(0.053)\end{array}$ \\
\hline Lag FTA & & $\begin{array}{l}0.152^{* *} \\
(0.053)\end{array}$ & $\begin{array}{c}0.113^{* *} \\
(0.055)\end{array}$ & $\begin{array}{c}0.073 \\
(0.061)\end{array}$ \\
\hline Lag2 FTA & & & $\begin{array}{c}0.071 \\
(0.069)\end{array}$ & $\begin{array}{c}0.039 \\
(0.080)\end{array}$ \\
\hline Lead FTA & & & & $\begin{array}{c}-0.024 \\
(0.057)\end{array}$ \\
\hline Cumulative FTA & 0.215 & 0.309 & 0.259 & 0.112 \\
\hline $\mathrm{CU}$ & $\begin{array}{l}0.544 * * \\
(0.054)\end{array}$ & $\begin{array}{l}0.299 * * \\
(0.054)\end{array}$ & $\begin{array}{l}0.313^{* *} \\
(0.054)\end{array}$ & $\begin{array}{l}0.355^{* *} \\
(0.056)\end{array}$ \\
\hline $\mathrm{Lag} \mathrm{CU}$ & & $\begin{array}{l}0.362 * * \\
(0.055)\end{array}$ & $\begin{array}{l}0.314^{* *} \\
(0.059)\end{array}$ & $\begin{array}{c}0.168^{* *} \\
(0.074)\end{array}$ \\
\hline $\mathrm{Lag} 2 \mathrm{CU}$ & & & $\begin{array}{c}0.076 \\
(0.072)\end{array}$ & $\begin{array}{c}0.076 \\
(0.073)\end{array}$ \\
\hline Lead CU & & & & $\begin{array}{c}0.030 \\
(0.060)\end{array}$ \\
\hline Cumulative $\mathrm{CU}$ & 0.544 & 0.661 & 0.627 & 0.523 \\
\hline Test FTA = CU & {$[p<0.001]$} & {$[p=0.014]$} & {$[p=0.003]$} & {$[p<0.001]$} \\
\hline $\begin{array}{l}\text { Test Lag FTA }=\text { Lag CU } \\
\text { Test Lag2 FTA }=\text { Lag2 CU } \\
\text { Test Lead FTA }=\text { Lead FTA }\end{array}$ & & {$[p<0.001]$} & $\begin{array}{l}{[p<0.001]} \\
{[p=0.943]}\end{array}$ & $\begin{array}{l}{[p=0.186]} \\
{[p=0.696]} \\
{[p=0.406}\end{array}$ \\
\hline Joint test & & {$[p<0.001]$} & {$[p<0.001]$} & {$[p<0.001]$} \\
\hline$N$ & 48,235 & 45,262 & 41,656 & 34,354 \\
\hline
\end{tabular}

once the more reliable PPML estimator is employed, the selection bias appears to matter only for FTAs and not CUs, and the overall selection bias is found to be positive for FTAs. Thus, the PPML results are consistent with a situation where the amount of positive selection into CUs is almost completely offset by an equal amount of negative selection. However, for FTAs, the negative selection effect is weaker, resulting in a net positive selection bias. The greater negative selection into CUs is plausible because it is typically assumed to be a more integrated trade regime and thus would lead to greater welfare gains in the presence of strong unobservables hindering bilateral trade (such as domestic shipping regulations). In light of such selection issues, it is essential to use both panel fixed effects and the PPML in order to draw reliable conclusions.

Panel Results after Splitting the Sample

Table 6 re-examines the findings in Table 4 by using the same lag and lead specifications, but after splitting the sample. While columns (a), (b), (c), and (d) report results using data from 1960 to 1985, results in (e), (f), (g), and (h) correspond to the years 1990 to 2000.The split addresses any tension between the time dimension of the data and the assumption of time-invariant unobservables. Accordingly, the results in Table 6 are less sensitive to the possibility of crucial unobservables varying over time. The results 
Table 6. Panel Estimates of the PPML Specification (including observations with zero trade), after Splitting the Sample

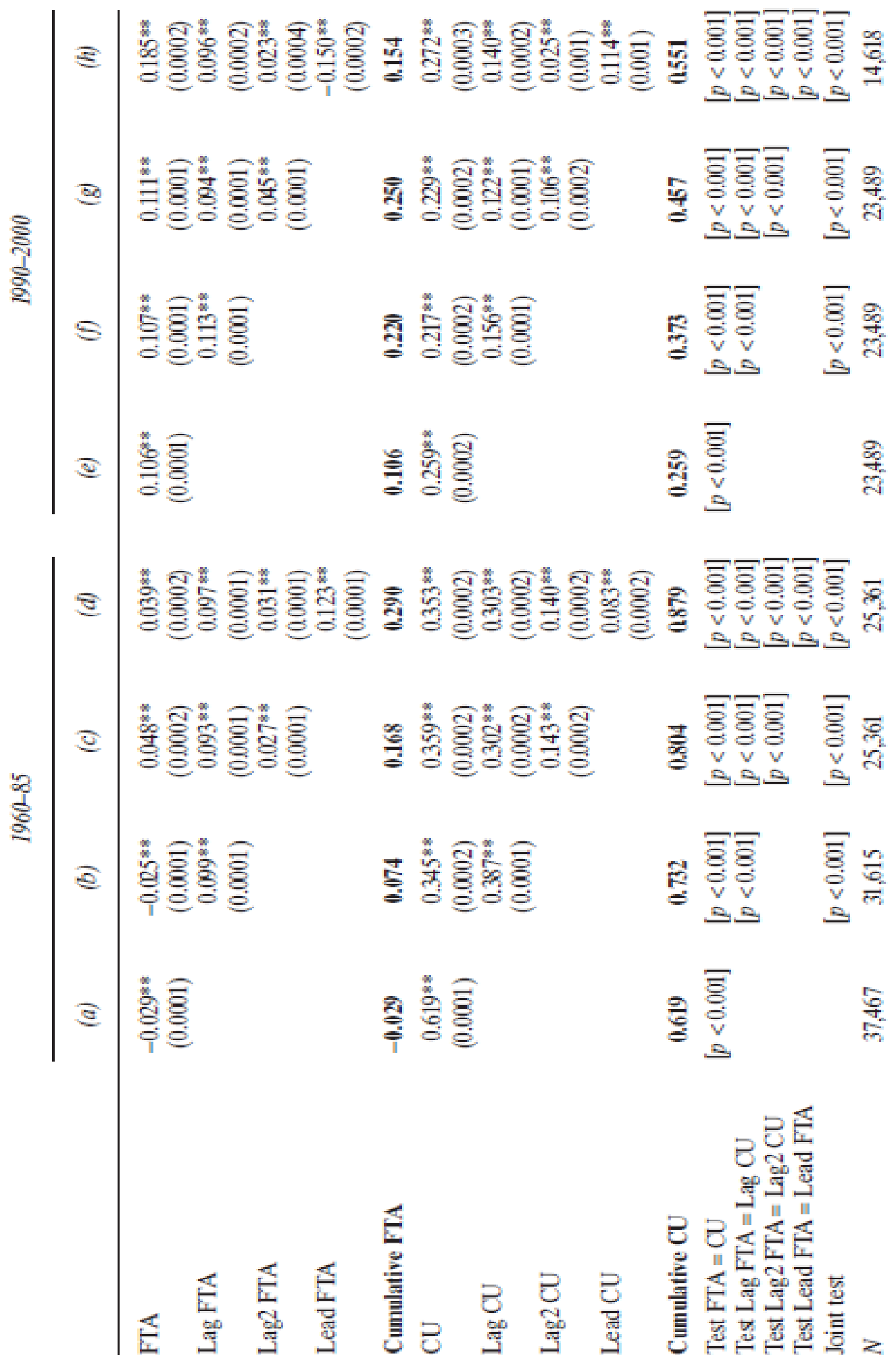

further strengthen the findings in Table 4. In both samples the contemporaneous and cumulative effects of a CU are significantly greater than those of an FTA. For the years 
1960 to 1985 , CUs more than double the volume of members' bilateral trade across all the specifications except (a), where the increase is by about $85 \%$. The differences in the FTA and CU coefficients are smaller when only the years 1990 to 2000 are considered. However, the ranking of the two PTA regimes, in terms of members' bilateral trade, remains unaltered.

For both samples in Table 6, individual and joint tests continue to reject the equality of the coefficients on the trade agreement dummies, and on their lag and lead terms. This finding for the 1990 to 2000 sample is especially interesting when compared to the cross-section test of equality results. Although cross-section results from the OLS specification suggest significant differences in the FTA and CU coefficients after 1970, the Table 3 results suggest the same, but up to 1970. However, once crucial unobservables are also controlled for, FTA and CU members are found to engage in significantly different volumes of bilateral trade, in more recent times as well. Incidentally, the OLS results in Table 7 also find CUs to promote more bilateral trade than FTAs.

\section{Panel Results after Controlling for EU}

According to Krueger (1999, p. 106), up to the late 1970s, the EU "was by far the most successful customs union." Hence, whether the EU's success is primarily responsible for this paper's findings, remains a relevant concern.Tables 8 and 9 aim to address this issue by considering a separate dummy variable for the EU. In other words, the EU variable takes the value one for a pair of EU countries, and zero otherwise. The CU dummy is assigned a value of one only to country pairs belonging to CUs other than the EU. However, the FTA variable remains unchanged. Given the previous findings, only the PPML method using the panel fixed effects method is relied on. Lags and leads, characteristic of the other panel tables, are also included. While Table 8 utilizes the entire sample, Table 9 considers a split similar to the one in Table 6.

The results are striking. Across all specifications using the full sample (Table 8), the cumulative effects are greatest for countries belonging to CUs other than the EU. Individual and joint tests continue to reject the null of equality, at the $1 \%$ level, for each pair of the trade agreement dummies. Hence, even the CU members, which do not belong to the EU, continue to engage in significantly greater volumes of bilateral trade than FTA members. The cumulative effects also find bilateral trade to be significantly greater for EU members relative to the FTA members. Most interestingly, EU members engage in significantly less bilateral trade than countries belonging to the other CUs. Thus, the EU does not influence the ranking of FTAs and CUs, previously obtained. Hence, the full-sample results suggest that the other CUs such as the CACM and the Caribbean Community (Caricom) were more successful in promoting bilateral trade. In fact, support for this argument can be found in Baier et al. (2007), who consider the CACM and the Caricom to have been successful CUs. Although, the CACM was mostly ineffective between the late 1970s and 1990, the Caricom remained continually effective. 
For the 1960 to 1985 sample, in Table 9, the volume of bilateral trade is significantly greater among the EU members, than countries belonging to FTAs or other CUs. Also, the cumulative effects in columns (a), (b), (c), and (d) fail to unambiguously rank members belonging to FTAs and other CUs. However, following a revival of the CACM and the continued success of the Caricom, CUs are found to promote the most bilateral trade for the period from 1990 to 2000. This is consistent with the claims of Krueger

Table 7. Panel Estimates of the OLS Specification (excluding observations with zero trade), after Splitting the Sample

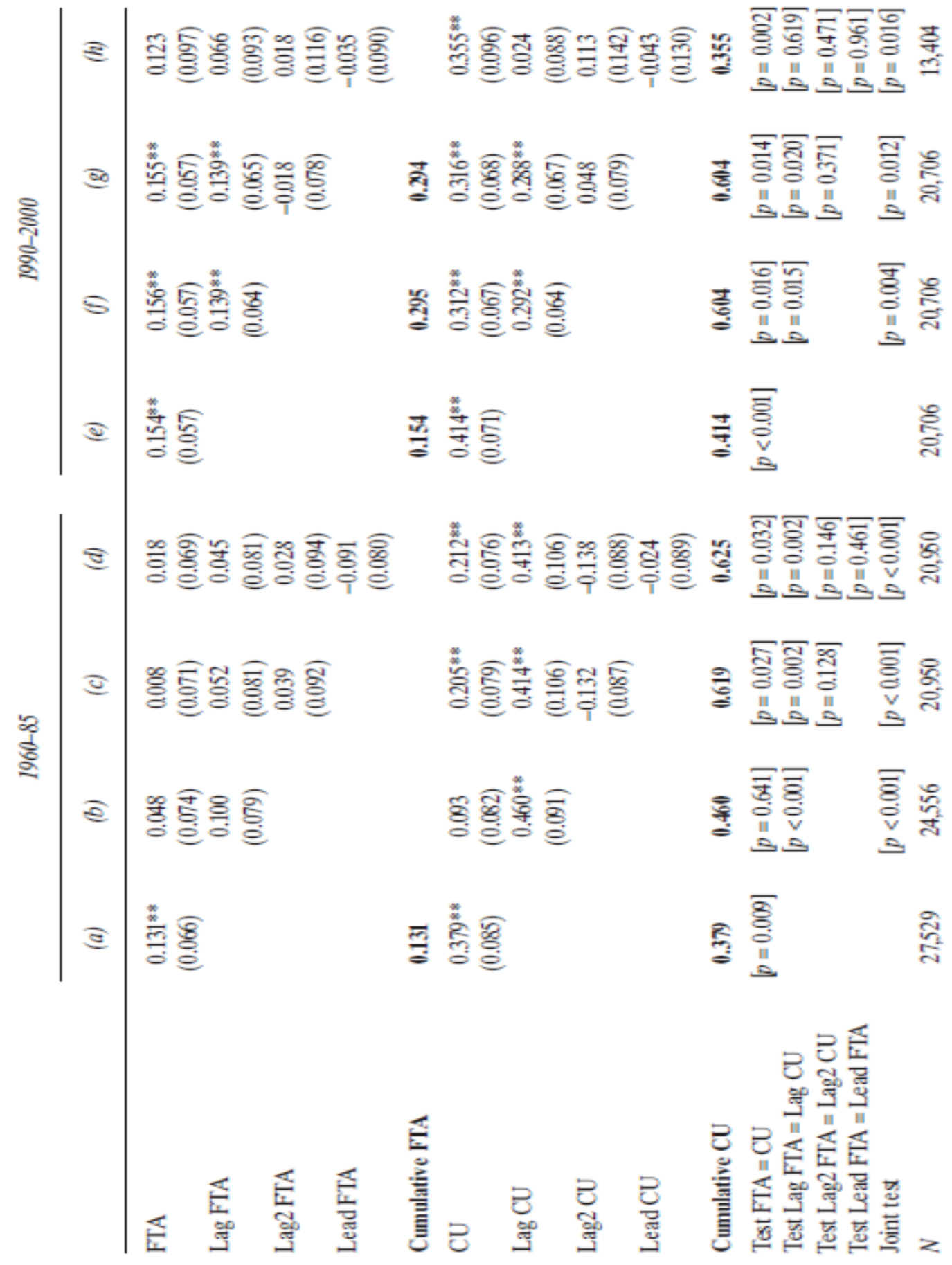


Table 8. Panel Estimates of the PPML Specification (including observations with zero trade)

\begin{tabular}{|c|c|c|c|c|}
\hline & (a) & (b) & (c) & (d) \\
\hline FTA & $\begin{array}{c}0.150^{* * *} \\
(0.0001)\end{array}$ & $\begin{array}{c}0.064^{* *} \\
(0.0001)\end{array}$ & $\begin{array}{c}0.069 * * \\
(0.0001)\end{array}$ & $\begin{array}{c}0.117 * * \\
(0.0001)\end{array}$ \\
\hline Lag FTA & & $\begin{array}{c}0.154^{* *} \\
(0.0001)\end{array}$ & $\begin{array}{c}0.129 * * \\
(0.0001)\end{array}$ & $\begin{array}{c}0.033^{* *} \\
(0.0001)\end{array}$ \\
\hline Lag2 FTA & & & $\begin{array}{c}0.029 * * \\
(0.0001)\end{array}$ & $\begin{array}{c}0.087^{* *} \\
(0.0001)\end{array}$ \\
\hline Lead FTA & & & & $\begin{array}{c}0.019 * * \\
(0.0001)\end{array}$ \\
\hline Cumulative FTA & 0.150 & 0.218 & 0.227 & 0.256 \\
\hline CU & $\begin{array}{r}0.777^{* *} \\
(0.0002)\end{array}$ & $\begin{array}{c}0.592^{* *} \\
(0.0002)\end{array}$ & $\begin{array}{c}0.597 * * \\
(0.0002)\end{array}$ & $\begin{array}{c}0.652^{* *} \\
(0.0004)\end{array}$ \\
\hline Lag CU & & $\begin{array}{c}0.400^{* *} \\
(0.0003)\end{array}$ & $\begin{array}{r}0.367 * * \\
(0.0003)\end{array}$ & $\begin{array}{l}-0.191 * * \\
(0.001)\end{array}$ \\
\hline $\mathrm{Lag} 2 \mathrm{CU}$ & & & $\begin{array}{l}0.337 * * \\
(0.001)\end{array}$ & $\begin{array}{l}0.722^{* *} \\
(0.001)\end{array}$ \\
\hline Lead CU & & & & $\begin{array}{c}0.355^{* *} \\
(0.0003)\end{array}$ \\
\hline Cumulative CU & 0.777 & 0.992 & 1.301 & 1.538 \\
\hline EU & $\begin{array}{r}0.546^{* * *} \\
(0.0001)\end{array}$ & $\begin{array}{r}0.267 * * \\
(0.0001)\end{array}$ & $\begin{array}{r}0.287^{* *} \\
(0.0001)\end{array}$ & $\begin{array}{r}0.347^{* *} \\
(0.0001)\end{array}$ \\
\hline Lag EU & & $\begin{array}{c}0.347 * * \\
(0.0001)\end{array}$ & $\begin{array}{c}0.209 * * \\
(0.0001)\end{array}$ & $\begin{array}{c}0.295^{* *} \\
(0.0001)\end{array}$ \\
\hline Lag2 EU & & & $\begin{array}{c}0.207 * * \\
(0.0001)\end{array}$ & $\begin{array}{c}0.142^{* *} \\
(0.0001)\end{array}$ \\
\hline Lead EU & & & & $\begin{array}{c}-0.008 * * \\
(0.0001)\end{array}$ \\
\hline Cumulative EU & 0.546 & 0.614 & 0.703 & 0.776 \\
\hline $\begin{array}{l}\text { Test FTA }=\text { CU } \\
\text { Test Lag FTA = Lag CU } \\
\text { Test Lag2 FTA = Lag } 2 \text { CU } \\
\text { Test Lead FTA = Lead CU }\end{array}$ & {$[p<0.001]$} & $\begin{array}{l}{[p<0.001]} \\
{[p<0.001]}\end{array}$ & $\begin{array}{l}{[p<0.001]} \\
{[p<0.001]} \\
{[p<0.001]}\end{array}$ & $\begin{array}{l}{[p<0.001]} \\
{[p<0.001]} \\
{[p<0.001]} \\
{[p<0.001]}\end{array}$ \\
\hline Joint test & & {$[p<0.001]$} & {$[p<0.001]$} & {$[p<0.001]$} \\
\hline $\begin{array}{l}\text { Test FTA = EU } \\
\text { Test Lag FTA = Lag EU } \\
\text { Test Lag } 2 \text { FTA = Lag } 2 \text { EU } \\
\text { Test Lead FTA = Lead EU }\end{array}$ & {$[p<0.001]$} & $\begin{array}{l}{[p<0.001]} \\
{[p<0.001]}\end{array}$ & $\begin{array}{l}{[p<0.001]} \\
{[p<0.001]} \\
{[p<0.001]}\end{array}$ & $\begin{array}{l}{[p<0.001]} \\
{[p<0.001]} \\
{[p<0.001]} \\
{[p<0.001]}\end{array}$ \\
\hline Joint test & & {$[p<0.001]$} & {$[p<0.001]$} & {$[p<0.001]$} \\
\hline $\begin{array}{l}\text { Test } \mathrm{CU}=\mathbf{E U} \\
\text { Test } \mathrm{Lag} \mathrm{CU}=\mathrm{Lag} \text { EU } \\
\text { Test Lag } 2 \mathrm{CU}=\mathrm{Lag} 2 \mathrm{EU} \\
\text { Test Lead } \mathrm{CU}=\text { Lead } \mathrm{EU}\end{array}$ & {$[p<0.001]$} & $\begin{array}{l}{[p<0.001]} \\
{[p<0.001]}\end{array}$ & $\begin{array}{l}{[p<0.001]} \\
{[p<0.001]} \\
{[p<0.001]}\end{array}$ & $\begin{array}{l}{[p<0.001]} \\
{[p<0.001]} \\
{[p<0.001]} \\
{[p<0.001]}\end{array}$ \\
\hline Joint test & & {$[p<0.001]$} & {$[p<0.001]$} & {$[p<0.001]$} \\
\hline$N$ & 67,058 & 60,531 & 53,707 & 44,014 \\
\hline
\end{tabular}

Table 9. Panel Estimates of the PPML Specification (including observations with zero trade), after Splitting the Sample

\begin{tabular}{|c|c|c|c|c|c|c|}
\hline & \multicolumn{4}{|c|}{$1960-85$} & \multicolumn{2}{|c|}{$1990-2000$} \\
\hline & (a) & (b) & (c) & (d) & (e) & (f) \\
\hline FTA & $\begin{array}{r}-0.030^{* *} \\
(0.0001)\end{array}$ & $\begin{array}{r}-0.026 * * \\
(0.0001)\end{array}$ & $\begin{array}{r}0.046 * * \\
(0.0002)\end{array}$ & $\begin{array}{c}0.038^{* * *} \\
(0.0002)\end{array}$ & $\begin{array}{r}0.073^{* *} \\
(0.0001)\end{array}$ & $\begin{array}{c}0.071 * * \\
(0.0001)\end{array}$ \\
\hline Lag FTA & & $\begin{array}{r}0.099=* \\
(0.0001)\end{array}$ & $\begin{array}{r}0.093^{* *} \\
(0.0001)\end{array}$ & $\begin{array}{c}0.097 * * \\
(0.0001)\end{array}$ & & $\begin{array}{l}0.111 * * \\
(0.0001)\end{array}$ \\
\hline Lag2 FTA & & & $\begin{array}{c}0.027^{* * *} \\
(0.0001)\end{array}$ & $\begin{array}{c}0.031 * * \\
(0.0001)\end{array}$ & & \\
\hline Lead FTA & & & & $\begin{array}{c}0.123 * * \\
(0.0001)\end{array}$ & & \\
\hline Cumulative FTA & -0.030 & 0.073 & 0.166 & 0.289 & 0.073 & 0.182 \\
\hline $\mathrm{CU}$ & $\begin{array}{r}-0.223^{* *} \\
(0.0001)\end{array}$ & $\begin{array}{c}-0.373 * * \\
(0.001)\end{array}$ & $\begin{array}{l}-0.244 * * \\
(0.001)\end{array}$ & $\begin{array}{c}-0.383 * * \\
(0.001)\end{array}$ & $\begin{array}{c}0.389 * * \\
(0.0003)\end{array}$ & $\begin{array}{c}0.360 * * \\
(0.0003)\end{array}$ \\
\hline Lag CU & & $\begin{array}{l}0.446 * * \\
(0.001)\end{array}$ & $\begin{array}{l}0.273^{* *} \\
(0.002)\end{array}$ & $\begin{array}{l}0.272^{* *} \\
(0.002)\end{array}$ & & $\begin{array}{l}0.151 * * \\
(0.0004)\end{array}$ \\
\hline $\mathrm{Lag} 2 \mathrm{CU}$ & & & $\begin{array}{l}-0.057^{* *} \\
(0.002)\end{array}$ & $\begin{array}{l}0.255^{* *} \\
(0.002)\end{array}$ & & \\
\hline Lead CU & & & & $\begin{array}{l}0.515 * * \\
(0.002)\end{array}$ & & \\
\hline Cumulative $\mathrm{CU}$ & -0.223 & 0.073 & -0.028 & 0.659 & 0.389 & 0.511 \\
\hline EU & $\begin{array}{r}0.630^{* * *} \\
(0.0001)\end{array}$ & $\begin{array}{c}0.360^{* *} \\
(0.0002)\end{array}$ & $\begin{array}{c}0.373^{* *} \\
(0.0002)\end{array}$ & $\begin{array}{c}0.367 * * \\
(0.0002)\end{array}$ & $\begin{array}{c}0.176 * * \\
(0.0002)\end{array}$ & $\begin{array}{l}0.121 * * \\
(0.0002)\end{array}$ \\
\hline Lag EU & & $\begin{array}{c}0.381 * * \\
(0.0001)\end{array}$ & $\begin{array}{c}0.300^{* *} \\
(0.0002)\end{array}$ & $\begin{array}{c}0.302 * * \\
(0.0002)\end{array}$ & & $\begin{array}{c}0.167 * * \\
(0.0001)\end{array}$ \\
\hline Lag2 EU & & & $\begin{array}{c}0.140^{* * *} \\
(0.0002)\end{array}$ & $\begin{array}{c}0.137^{* * *} \\
(0.0002)\end{array}$ & & \\
\hline Lead EU & & & & $\begin{array}{c}0.083 * * \\
(0.0002)\end{array}$ & & \\
\hline Cumulative EU & 0.630 & 0.741 & 0.813 & 0.889 & 0.176 & 0.288 \\
\hline$N$ & 37,467 & 31,615 & 25,361 & 25,361 & 23,489 & 23,489 \\
\hline
\end{tabular}


(1999) and BB (2009), who consider the EU effect to diminish after 1970. As a result, other CUs are found to encourage more bilateral trade in the 1990 to 2000 sample.

\section{Conclusion}

Analyses pertaining to FTAs and CUs are significant for trade policy decisions. The policy issue seems to be of even greater relevance today, when Fiorentino et al. (2007) consider CUs to be characterized by declining popularity. This paper is the first empirical contribution to directly compare the two PTA regimes while addressing biases due to crucial time-invariant unobservables and log-linearization of the gravity model. While BB (2007) address the former, the latter is found to be of significant relevance as well. Once both biases are addressed, the results are striking. BB (2007, p. 72) find that, "on average, an FTA approximately doubles two members' bilateral trade after 10 years." However, this paper uses the same data, concluding that it is actually a CU that is responsible for this.

In general, members of a CU are found to engage in significantly greater volumes of bilateral trade than FTA members. Strikingly, the finding remains unaltered on controlling for a separate EU effect, or on splitting the sample. Although some of the initial success of CUs can be attributed to the EU, the latter's prominence disappears in more recent years.

\section{Appendix}

Table A1. List of Customs Unions and Free-Trade Agreements

Customs Unions

European Union, or EU (1958): Belgium-Luxembourg, France, Italy, Germany, Netherlands, Denmark (1973), Ireland (1973), United Kingdom (1973), Greece (1981), Portugal (1986), Spain (1986), Austria (1995), Finland (1995), Sweden (1995)

Central American Common Market (1959*-75, 1993): El Salvador, Guatemala, Honduras, Nicaragua, Costa Rica (1965)

Economic and Customs Union of the Central African States (1991**): Cameroon, Congo, Gabon

Caribbean Community, or Caricom (1973***): Jamaica, Trinidad \& Tobago, Guyana (1995)

Mercosur (1991): Argentina, Brazil, Paraguay, Uruguay

Andean Community (1993): Bolivia, Colombia, Ecuador, Venezuela, Peru (1997)

EU-Turkey (1996†)

Free Trade Agreements

Customs Union of West African States (1959-66†): Burkina Faso, Mali, Mauritania, Niger, Senegal, Cote d'Ivoire

European Free Trade Association, or EFTA (1960): Austria (until 1994), Denmark (until 1973), Finland (1986-94), Norway, Portugal (until 1986), Sweden (until 1994), Switzerland, United Kingdom (until 1973)

Economic and Customs Union of the Central African States (1966-90**): Cameroon, Congo, Gabon

Caribbean Community, or Caricom (1968-73***): Jamaica, Trinidad \& Tobago

EU-EFTA/European Economic Area (1973/94)

Australia-New Zealand Closer Economic Relations (1983)

US-Israel (1985)

US-Canada (1989)

EFTA-Turkey (1992) १

EFTA-Israel (1993)

Central Europe Free Trade Agreement, or CEFTA (1993): Hungary, Poland, Romania (1997), Bulgaria (1998)

EFTA-Bulgaria (1993)

EFTA-Hungary (1993)

EFTA-Poland (1993) 
Table Al. Continued

Free Trade Agreements (Continued)

EFTA-Romania (1993)

North American Free Trade Agreement, or NAFTA (1994): Canada, Mexico, United States

Bolivia-Mexico (1995)

Costa Rica-Mexico (1995)

Group of Three (1995): Colombia, Mexico, Venezuela

Mercosur-Chile (1996)

Mercosur-Bolivia (1996)

Canada-Chile (1997)

Canada-Israel (1997)

Association of South East Asian Nations, or ASEAN (1998): Indonesia, Philippines,

Singapore, Thailand

Caricom-Dominican Republic (1998)

Hungary-Turkey (1998)

Israel-Turkey (1998)

India-Sri Lanka (1998)

Hungary-Israel (1998)

Mexico-Nicaragua (1998)

Poland-Israel (1998)

Romania-Turkey (1998)

EU-Tunisia (1998) †

EFTA-Morocco (1999)市

Mexico-Chile (1999)

Common Market for Eastern and Southern Africa, or Comesa (2000): Egypt, Kenya,

Madagascar, Malawi, Mauritius, Sudan, Zimbabwe, Zambia

EU-Israel (2000)

EU-Mexico (2000)

Poland-Turkey (2000)

Mexico-Guatemala (2000)

Mexico-Honduras (2000)

Mexico-Israel (2000)

Mexico-El Salvador (2000)

New Zealand-Singapore (2000)

EU-Morocco (2000)

Notes. The parentheses contain an agreement's year of entry, except where noted otherwise.

* Frankel $(1997$, p. 262$)$ considers the formation year to be 1959.

** Frankel (1997, p. 274) considers the union to have been functioning as little more than an FTA up to 1991. *** According to Frankel (1997, p. 261), initially an FTA (Carifta) was formed in 1968 followed by a CU in 1973.

† http//www.wto.org/english/tratop_e/region_e/summary_e.xls.

7t Frankel (1997, p. 275) suggests the existence of an FTA till 1966 followed by little success.

thttp:/www.wto.org/english/tratop_e/region_e/summary_e.xls. Although EU-Hungary, EU-Bulgaria, EU-Poland, EU-Romania are listed in Baier and Bergstrand (2007), they are not considered to be total agreements in their data. Jeffrey Bergstrand verifies this, and they are not listed in http://www.wto.org/ english/tratop_e/region_e/summary_e.xls as well. Frankel (1997, p. 259) suggests that the Latin American Free Trade Association (LAFTA) met with little success. Also, its successor, the Latin American Integration Association (LAIA) is considered to be partial scope. Hence they have not been listed here. Owing to its very limited success, the African Common Market is also not coded as an FTA or a CU. 


\section{References}

Anderson, I. E. and E. Van Wincoop (2003). Gravity with gravitas: a solution to the border puzzle. 93.

Baier Scott, L. and H. Bergstrand Jeffrey (2009). Estimating the Effects of Free Trade Agreements on Trade Flows using Matching Econometrics. 77: 63-76.

Baier, S. L. and J. H. Bergstrand (2007). Do free trade agreements actually increase members' international trade? 71: 72-95.

Baier, S. L., et al. (2008). Do economic integration agreements actually work? Issues in understanding the causes and consequences of the growth of regionalism. 31: 461-497.

Baier, S. L., et al. (2007). Free trade agreements in the Americas: are the trade effects larger than anticipated? 30: 1347-1377.

Bhagwati, J. and A. Panagariya (1999). Preferential Trading Areas and Multilateralism--Strangers, Friends, or Foes? Trading Blocs B2 - Trading Blocs. Cambridge, MIT Press.

Clausing Kimberly, A. (2000). Customs Unions and Free Trade Areas. 15: 418-435.

Fiorentino Roberto, V., et al. (2007). The Changing Landscape of Regional Trade Agreements: 2006 Update B2 - The Changing Landscape of Regional Trade Agreements: 2006 Update.

Frankel, J. (1997). Regional Trading Blocks B2 - Regional Trading Blocks. Washington, DC, Institute for International Economics.

Ghosh (2004). Does Trade Creation Measure Up? A Reexamination of the Effects of Regional Trading Arrangements. 82: 213-219.

Haveman, J. and D. Hummels (1998). Trade creation and trade diversion: new empirical results. 3: 47-72.

Henderson, D. J. and D. M. Millimet (2008). Is gravity linear? 23: 137-172.

Krueger, A. (1999). Are Preferential Trading Arrangements Trade-liberalizing or Protectionist? 13: 105124.

Krueger, A. O. (1997). Free trade areas versus customs unions. 54.

Liu, X. P. (2009). GATT/WTO promotes trade strongly: Sample selection and model specification. 17: 428446.

Magee Christopher, S. P. (2003). Endogenous Preferential Trade Agreements: An Empirical Analysis. 2.

Magee Christopher, S. P. (2008). New Measures of Trade Creation and Trade Diversion. 75: 340-362.

Santos Silva, J. M. C. and T. Silvana (2006). The log of gravity. 88: 641-658. 